\title{
Simulation Analysis for Maximizing Renewable Solar Energy to Improve the Power Generation Capacity in the State of Kuwait
}

\author{
${ }^{1}$ Naser A. N. Muhaisen, ${ }^{2}$ Sheroz Khan, 3 Zeyad M. A. Ismail, ${ }^{4}$ Mohamed H. Habaebi, \\ ${ }^{5}$ Nabil A. Ahmed, ${ }^{6}$ Musse Mohamud Ahmed \\ 1, 2,4 Department of Electrical and Computer Engineering, International Islamic University Malaysia, Malaysia \\ ${ }^{6}$ Electrical and Electronics Engineering Department, Faculty of Engineering, UNIMAS, Sarawak, Malaysia \\ ${ }^{5}$ Department of Electrical Engineering, Faculty of Technological Studies, Shwwaikh, Kuwait \\ ${ }^{3}$ Mechatronics Department AMA International University. Bahrain \\ ${ }^{1}$ failakawe75@gmail.com
}

\begin{abstract}
This paper aims to present how to improve power generation capacity in the State of Kuwait through simulation analysis for maximizing the usage of renewable energy applications. Power demand in Kuwait increases every year by $6 \%$ that causes load-shedding problems in the national utility grid system. An effective solution is proposed in this paper to enhance the power demand shortage which leads to reduce the effects of load demands excesses, by employing some solutions in the field of solar energy system. The on-grid solar energy system to be spread on roof of buildings connected to utility grid in Kuwait is a fantastic solution for backing up the increasing power demand. In this paper, the research work is directed towards the study of new approach by adopting power generation system based on PV on-grid systems installed on rooftops of commercial and residential buildings. The system performance analysis is carried out by choosing Mono crystalline PV modules using PSIM software simulation. This simulation covers the analysis of power generated by the PV system as an input passing through a selected maximum power point tracker (MPPT) to achieve the maximum energy output. A control algorithm for power regulation has been developed with maximum power generation of enhanced $\mathrm{AC}$ power grid with power factor close to unity. A reliable tracker for the power output was shown by the simulation results generated by the model.
\end{abstract}

Keywords-power generation; renewable energy; loadshedding; Mono crystalline PV model; PSIM software

\section{INTRODUCTION}

Renewable energy sources of solar, wind, ocean waves energy offer alternatives to conventional fossil fuel and crude oil based electricity generation. Solar stands next to wind as one of the most prominent recent choices in renewable energy, which has been becoming the most feasible option due to affordable solar energy system products. The sun's radiation on the earth reaches to the aimed surface about $1 \mathrm{kwatt} / \mathrm{square}$ meter on a clear day. The main points raised in supporting of using solar electric power are summarized as in [1] as consisting of:

A. Clean: no harmful emissions are produced as a Carbon free source.
B. Abundant: Low-carbon, clean, green and renewable energy is gained from PV panels which can be used as an electric supply for homes or buildings.

C. Dependable: The costs of power system based on solar energy potentially remain fixed while conventional power generation depends on fossil fuels, which remain increasing over the years. The solar power is proven as a highly reliable; it has a lifetime of about 20 to 25 years, and it may last until 30 to 40 years of age or longer. Besides it does not suffer from issues of price instability related to fuel prices fluctuations.

D. Distributed: most of the places, solar energy is available, particularly in rural areas and at remote locations which is the best alternative source of electric energy while its cost is coming down substantially.

E. Sustainable Indefinitely, the solar power technology proves to be the alternative to provide electricity for our world [2].

\section{SOlAR RADIATION IN KUWAIT}

In Kuwait solar power occurs in the months of April-to-October, the months when power is needed the most as shown in Figure 1. The Ministry of Energy and Water (MEW), currently relying on seven power plants has been investing in more run by oil and natural gas as shown in Figure 2. The huge demand for power consumption is most from residential followed by government and industry as shown in Figure 3. The peak demand in the AprilOctober months needs be met rom alternative sources.

The hours of sunshine per day in Kuwait, are quite abundant and receive huge sum of solar radiations particularly in the summer period. Monthly Averaged Solar Radiation on horizontal surfaces is shown in Figure1 where the annual peak is in the band between April and October. 